2017-11

\title{
Constructing accounts of organisational failure: Policy, power and concealment
}

Sheaff, Mike

http://hdl.handle.net/10026.1/10672

$10.1177 / 0261018316681252$

Critical Social Policy

SAGE Publications

All content in PEARL is protected by copyright law. Author manuscripts are made available in accordance with publisher policies. Please cite only the published version using the details provided on the item record or document. In the absence of an open licence (e.g. Creative Commons), permissions for further reuse of content should be sought from the publisher or author. 
Final author's draft of a paper published in Critical Social Policy 2017 Vol. 37 Iss. 4 pp: 520-539, (first published online in Dec. 2016). DOI: https://doi.org/10.1177/0261018316681252

Constructing accounts of organisational failure: policy, power and concealment

\section{Abstract}

An example of contracting arrangements within the National Health Service (NHS) provides the focus for considering accounts of organisational behaviour and failure. Public accounts of the outcome are contrasted with information disclosed in response to Freedom of Information Act (FOIA) requests. While the former focused on shortcomings in commercial expertise, sometimes at lower levels within organisational hierarches, the latter suggests a need to consider the environment of social networks and power relationships.

The data suggest obstacles to information flows across organisational boundaries were a contributory cause of failure, but a desire to present the implementation of policy in a positive light encouraged subsequent concealment of what Goffman described as 'dark secrets' (Goffman, 1959/1990). Through this example, the article provides an exploratory use of FOIA to examine social processes that frequently elude investigation.

Keywords: Power; Information; Secrecy; 
A belief that competition promotes efficiency and quality of public services has prompted increased use of external contracts by Labour, Coalition and Conservative Governments. By 2014-15, the NHS spent nearly £7.5 billion on contracts with external providers (Department of Health, 2015). Freedom of Information requests to Clinical Commissioning Groups (CCG's) submitted by the Labour Party disclosed that, 'of 5,071 contracts awarded by CCGs 2,098 (41\%) went to NHS bodies and $2,024(40 \%)$ went to private healthcare firms.' (Campbell, 2015). However, it can be difficult to subject these arrangements to effective scrutiny. Asked for details on numbers of contracts held, one government Minister responded, 'the information requested is not held centrally. Individual commissioners (clinical commissioning groups and NHS England) are responsible for taking fair and transparent decisions on the award of contracts to the providers most capable of meeting the needs of their populations and providing value for money.' (Earl Howe, 2014, Hansard,12 May 2014 : Column WA464 ).

Official reviews of contracting focus upon implementation rather than underlying assumptions about market behaviour. Contracting failures are typically attributed to lack of commercial expertise in the public sector, with one account noting, 'One of the main conclusions of the government's commercial capability reviews was that there was insufficient focus on managing the contracts once the deal had been signed.' Urging, 'greater transparency of performance and costs, and use of open book accounting and internal audit', it suggested there was, 'a wider civil service culture which does not sufficiently value commercial expertise.' (Public Accounts Committee, 2016).

However, a focus upon commercial skills neglects social relations within which markets operate. Social networks and power relationships have particular salience as, 'traditional boundaries between state and market have dissolved', creating what has been described as a 'revolving-door' between public and corporate sectors (Wilks-Heeg, 2015: 142). For example, after being Secretary of State for Health, Patricia Hewett became a Board member of Boots UK Ltd, and of health care provider Cinven Ltd (Whyte, 2015). Secretly filmed by a Channel 4 researcher purporting to want contact with officials on behalf of a private health company, Hewitt commented, 'You need to have a sort of eye for propriety and all of that ... But I 
mean I have regular lunches and coffees and you know, we're all mates really.' (House of Commons, 2010.)

To explore the social and political environment in which contracting decisions are made, this article offers an account of a NHS service contracted out to a social enterprise. Secure Healthcare Ltd (SHL) was awarded a contract in 2007 for the provision of prison health care, attracting funding from the Department of Health $(\mathrm{DH})$, but collapsed within two years with substantial debts. Defined as a matter for the Primary Care Trust (PCT), DH was reluctant to reflect publicly on the episode:

'The Department of Health would not comment on the insolvency, but confirmed there would be no let-up in its commitment to social enterprise companies being part of the "plural and diverse" market delivering health and social services' (Gould, 2009).

Drawing upon the work of Diane Vaughn $(1996,1999)$ on how things go wrong in organisations, the article challenges assumptions that markets typically provide effective mechanisms for handling complex information. Information flows can be both obstructed and facilitated by social and organisational relationships within which markets are embedded. One feature is what Diane Vaughn describes as 'structural secrecy': 'the way that patterns of information, organizational structure, processes and transactions, and the structure of regulatory relations systematically undermine the attempt to know and interpret situations in all organisations.' (Vaughn, 1996: 238). However, informal social networks may frequently co-exist alongside these structures, providing largely invisible routes for the exercise of power, through shaping the context in which decisions are made. This can include the emergence of the 'normalisation of deviance' (Vaughn, 1996: 296), a gradual process of adopting unacceptable practices which, in the absence of negative consequences, become the norm. Neglect of this in official accounts reflects the 'prestige of authority' (Durkheim in Lukes, 1969) and 'hierarchy of credibility', whereby 'members of the highest group have the right to define the way things really are' (Becker, 1967: 241).

Accounts will at times be constructed with the intention of concealing sources of failure. In an analysis of the 1985 Challenger spacecraft disaster, Vaughn describes the communication failings between NASA teams (structural secrecy), but notes, 
Final author's draft of a paper published in Critical Social Policy 2017 Vol. 37 Iss. 4 pp: 520-539, (first published online in Dec. 2016). DOI: https://doi.org/10.1177/0261018316681252

'after the disaster, it appeared that Marshall managers intentionally concealed information' (Vaughn, 1996: 238). This recalls Goffman's observation on what he called 'dark secrets':

'facts about a team which it knows and conceals and which are incompatible with the image of self that the team attempts to maintain before its audience. . . The audience must not acquire destructive information about the situation that is being defined for them.' (Goffman, 1959/1990: 141).

Constructing accounts of organisational failure involves the 'mobilisation of bias', (Bachratz and Baratz, 1962: 952), in which, 'some issues are organized into politics while others are organized out' (Schattschneider, 1960: 71). The organizing out of issues contributes to a public discourse in which market failure is attributed to technical or exogenous factors, deflecting attention from the social and power relations that shape decisions. This article contrasts official explanatory accounts for SHL's collapse with information obtained through Freedom of Information Act (FOIA) requests. Providing access to otherwise concealed 'back stage' knowledge (Goffman, 1959/1990), these allow attention to be given to the performance of what Vaughn describes as 'clean-up work':

'Employees and organisations devote enormous resources to prevent incidents of routine nonconformity from being publicly defined as mistake. This, too, is worthy of research. The social organisation of clean-up work also has social costs that eventually are paid by the public.' (Vaughn, 1999: 287).

Power can be constituted through the construction of accounts, as Garfinkel (1967) illustrated in an analysis of clinical records. Garfinkel contrasted 'actuarial records' with those providing a 'record of a therapeutic contract' (Garfinkel, 1967: 199). The latter highlights what might be expected to form part of this 'contract', and Garfinkel observed how, 'various items of the clinic folders are tokens - like pieces that will permit the assembly of an indefinitely large number of mosaics'. Elements are later selected to 'make a case' for clinical activity (1967: 202-203), enabling the use of records to support subsequent decisions. A similar point can be made about documents obtained in this study. Records were generally kept (with some notable exceptions), and used in public accounts to focus upon aspects such as commercial 
expertise. In contrast, the role of managerial hierarchies and networks, and the political context is missing. As Garfinkel observed, records, 'are integral features of the same social orders they describe' (Garfinkel, 1967: 192). This case study suggests that in reflecting the dominant social order, official accounts of SHL's collapse present the, 'over-communication of some facts and the undercommunication of others' (Goffman, 1959: 141). In contrast, information gained through FOIA disclosures allows an alternative account, challenging official versions in ways that raises important questions about analysis and accountability.

The policy context

In October 2006, DH's new Social Enterprise Unit (SEU) announced a 'Pathfinder' programme to stimulate innovation in service delivery. 381 applications were received. Initial sifting was made against three broad criteria:

'was it proposing a social enterprise business model?; did the proposal have commitment from a commissioner, or a viable commercial financial model?; was the proposal for a new service in health and social care or a new way of providing an existing service?' (HC Hansard, 8 February 2007, c1207W).

159 applications were removed in the first sift. Remaining applications were passed to Strategic Health Authorities (SHA's) for regional assessment, a stage that saw the removal of a further 177 applications (Royal College of Nursing, 2007). A final review by $\mathrm{DH}$ identified 26 successful bids. Each would receive support, including start-up funding. One of the successful organisations was Secure Healthcare Ltd (SHL), led by a former nurse and behavioural therapist with a commitment to mutualism and improving prison health care (Gould, 2008). SHL, established as an Industrial and Provident Society, proposed to provide and co-ordinate health care services at the UK's largest prison, HMP Wandsworth. DH provided a start-up grant of $£ 130,000$.

SHL had genuine ambitions to improve prison healthcare. Wandsworth prison, including its health care services, received a highly critical inspection in 2004 (HMIP, 2004) and an inspection in 2006 delivered further negative assessments. Prison 
healthcare transferred from the Home Office to the NHS in the intervening period, but the report suggested, 'The commissioning of healthcare services by Wandsworth Primary Care Trust (PCT) was underdeveloped ... Clinical governance arrangements were weak. . Recruitment and retention of staff was a key problem.' (HMIP, 2006: 46-47).

The PCT invited external providers to bid for provision of the service, with SHL submitting the successful tender, and commencing the contract in July 2007. The organisation, chaired by a former SHA chief executive, was launched in May 2007 by the Parliamentary Under Secretary of State for Care Services at The Cinnamon Club (SHL, 2009a: 4), a venue described as, 'the favourite of politicians and television producers' (Independent, 2011) and, 'a top location where journalists lunch with politicians' (Singh, 2008). Little more than two years later, SHL's collapse prompted Wandsworth Borough Council's Overview and Scrutiny Committee to express, 'particular concern in view of the impending externalisation of PCT provider services and the shift to a system in which a much higher proportion of community healthcare services will be secured through competitive tendering.' (Wandsworth Borough Council, 2009).

\section{Methodology}

The study was initially prompted by experiences raising questions when I was a NonExecutive Director in the NHS. Meeting resistance, I moved status from participant to researcher, collecting two types of data. The first comprised public accounts relating to the SHL contract. This included SHL's financial accounts, available from the Financial Services Agency which had regulatory responsibility for Industrial and Provident Societies. Particular attention is given to a report produced by Wandsworth PCT following SHL's collapse. A search of media reports was also undertaken. This was followed by a series of FOIA requests. Writing in the US, Keen suggests that the social scientific community's reliance upon official publications limits research data, urging greater use of FOIA requests (Keen, 2004: 5). Keen used the US FOIA, introduced in 1966, to obtain disclosure of information held by the FBI about sociologists (Keen, 2004). In the UK, a review of the use of FOIA's in 
social research suggests it, "potentially extends the range of resources available to social scientists, and the experience of researchers in other countries suggests that it will be capable of providing a viable source of data for social research.' (Lee, 2005: 15). Some researchers note limitations, and Brown concludes, 'Fol is not a cure-all to the problems of access and disclosure with which researchers have always struggled, but it does give them an important lever when dealing with the traditionally secretive agencies of the public sector.' (Brown, 2009: 90).

Under UK law, the process of seeking disclosure through FOIA requests involves up to five stages. Many months and longer can elapse before the procedure is completed:

1. Request for disclosure

2. Request for Internal Review

3. Complaint to Information Commissioner

4. Appeal to Information Rights Tribunal (Lower Tier)

5. Appeal to Information Rights Tribunal (Upper Tier) (on points of law)

In this study, nine out of 23 requests submitted to nine public authorities resulted in requests for internal reviews. Two continued to appeals to the Information Commissioner and the Information Rights Tribunal. I also submitted requests to three organisations for my 'personal data' under the Data Protection Act. Analysis of the information was guided by four criteria proposed by Scott (1990) for interpreting documentary records: authenticity, credibility, meaning and representativeness. All records were considered authentic, in the sense of being genuine, but it was necessary to consider the purpose for which they were constructed, when they were produced and for whom. It was the credibility of the records that is of greatest importance. Two dimensions of credibility were considered: 'the extent which an observer is sincere in the choice of a point of view and ... the attempt to record an accurate account from that chosen standpoint' (Scott, 1990: 22). Sincerity - 'whether the author of the document actually believed what he or she recorded' - is not a guarantee of accuracy (Scott, 1990: 22-23). Comparison of public accounts with disclosed information suggested the concealment of 'dark secrets', providing a means to consider accuracy, sincerity and meaning, including the performance of 'clean up work'. 
By approaching nine NHS organisations, disclosures provide a measure of assurance that the information is representative of the decision-making processes. It would be unjustified to assume documents relating to a single case study could be representative of the extensive contracting-out of NHS services, but features of this case suggest a broader relevance. It was part of a large $\mathrm{DH}$-sponsored programme, and the effort expended in discouraging my research, described later, directs attention to social practices through which power is used to conceal 'dark secrets'. Success will avoid questions.

Disclosure of information in response to a FOIA request can be in the form of original documents, or simply the information itself. In this article all such sources are cited as 'FOIA'. For complete documents, this is followed by the public authority's name and year of original publication, with details provided according to Harvard conventions. Where information, rather than a document, was disclosed, this is identified by citing the public authority and date of disclosure. This provides sufficient detail for others to request the information from the relevant authority, allowing opportunity to scrutinise interpretations offered here.

Two important ethical issues were considered. First, some writers have expressed fears that use of FOIA legislation may produce conflict and threaten the goodwill required for effective field work. Lee notes, 'Formal complaints about noncompliance, whilst legally possible, might, in the context of an ethnographic study, produce adversarial field relations.' (Lee, 2005: 12). Given the origins of this research, a change in role from participant to researcher brings a special responsibility to ensure integrity in the collection and analysis of data, but having failed to obtain information though alternative routes, I judged this an appropriate method. The second issue was informed consent. This cannot exist where information is disclosed reluctantly in the face of possible challenge through use of legislation. There is an analogous relationship with covert observation which can be ethically justified in certain circumstances. The caveat normally applied is that, 'in such studies it is important to safeguard the anonymity of research participants.' (British Sociological Association, 2002).

In this article, names of individuals are excluded, but to apply anonymity to organisations would negate the objective of comparing public accounts with 
information gained through FOIA disclosure. It would effectively maintain concealment. Once data is disclosed in response to FOIA requests it is in the public domain, and the response from my institution's ethical approval committee was that use of documentary data that has entered the public domain did not raise the usual ethical issues applicable to research involving human participants. I judged it appropriate to adopt an approach to researching power described by Phil Scraton:

'Given the structural determining contexts of power, guarantees of confidentiality, privacy and revision cannot be offered to those who represent and protect the interests of corporate bodies or state institutions. A form of "public interest defence", more often attributed to investigative journalism, should apply to critical research into alleged abuses of power. . . the "public interest" ends justify means which, in ethical terms, violate the principles of securing informed consent from all participants.' (Scraton, 2004: 191).

Public accounts of failure

When I raised concerns about the contracting arrangements with my Member of Parliament, he was advised these, 'are about contractual arrangements between Secure Healthcare Ltd and NHS South West London. The decision to award the contract and financial monitoring are a matter for those organisations.' (Minister of State, 14.11.12). A review by Wandsworth PCT, providing the fullest public account of the collapse, highlights shortcomings in commercial expertise, concluding that, 'Directors and Officers involved in the original procurement process were not then sufficiently experienced in the commercial externalisation of healthcare services to recognise the type of inherent risks faced or their extent' (NHS Wandsworth, 2009: 19). Nearly seven pages are devoted to an account of the process leading to the Evaluation Panel's recommendation of SHL as preferred bidder. Much of the focus is upon technical features of the process, notably the scoring methodology, which placed SHL third out of six bidding organisations.

The review notes concerns about entering the contract that appear to have been disregarded. At an early stage in the contracting process a member of the PCT's 
finance team informed SHL: 'The PCT is unable to enter into any financial or contractual arrangement with an organisation which has no trading history. Any such arrangement would be too much of a risk for the PCT.' (NHS Wandsworth, 2009: 5). This was challenged by SHL, which was advised to, 'proceed on the grounds that the published bid evaluation criteria did not include a requirement of this kind.' The report adds: 'Not all of the Evaluation Panel members were aware of these issues when the bid evaluation was taking place.' (NHS Wandsworth, 2009: 5).

Some issues raised during the commissioning process were not fully documented. Concerns about 'structure and governance arrangements' were raised at a PCT Board meeting, but the review notes:

'There is no further documentary evidence available that sets out exactly what these related to, other than a cryptic reference in one email: "concerns about governance and financial flows which we will need to address in the next stage". But none of those interviewed can directly recall exactly what may have been required.' (NHS Wandsworth, 2009: 11).

A decision to renew the contract was made in the summer of 2009, following a presentation by SHL staff of, 'extracts from their full audited accounts for the year ended on 31 March 2008. These gave no indication of any financial problems.' (NHS Wandsworth, 2009: 13). Certainly, SHL's Annual Return and Accounts, covering the first 14 months of its existence, to 31 March 2008, do not portray an organisation in financial difficulty. The income and expenditure account shows a turnover of $£ 4,500,424$, with expenditure of $£ 4,025,093$, and a balance carried forward of $£ 475,331$. The balance sheet reports liabilities of $£ 765,076$ (creditors), against assets of $£ 1,228,793$, comprising debtors of $£ 452,489$ and cash reserves of $£ 776,304$ (SHL, 2009a).

However, the review also reveals that some within the PCT were aware of financial difficulties. Within ten months of commencing the contract, SHL was submitting advance invoices. On 2 May 2008 an invoice requested payment for July, and on 5 May an invoice was submitted for August. The position worsened, and the review describes an, 
'apparent lack of awareness of both Finance and Commissioning staff ... that as far back as July $2008 \mathrm{SHL}$ were stating that they could not cover their wages bill without having the following month's invoice paid in advance.' (NHS Wandsworth, 2009: 16).

Suggesting the role of structural secrecy (Vaughn, 1996) limiting information sharing, the review notes that the PCT, 'received no indication from other NHS Partners that they were experiencing increasing payment difficulties prior to SHL ceasing to trade'. It refers to a, "lack of other "rumour" ... Informal rumours were generally positive, and senior PCT staff did not hear rumours of financial instability.' (NHS Wandsworth, 2009: 16). Nevertheless, referring to advance payments, concern is expressed about the PCT's, 'clearly stated contract payment arrangements having been altered without the approval of the Director of Finance.' (2009: 16). Illustrating the 'normalisation of deviance' (Vaughn, 1996: 296), there appears to have been a process of adopting unacceptable practices which became the norm. The review does not address the question of why procedures were not followed and documentary records not created. Explaining the normalisation of deviance requires going beyond a focus upon commercial expertise, to explore the role of power and networks in shaping the organisational environment in which decisions were made. In terms of credibility (Scott, 1990), Wandsworth PCT's review appears sincere, but its accuracy is constrained by an exclusive focus upon the contractual relationship between the PCT and SHL. For example, SHL's Annual Accounts identify $£ 467,000$ received for an 'X-Ray Project', and one of SHL's directors is described as being on 'DH secondment' (SHL, 2009a: 6). No reference to this is made in the PCT review, and this information may not have been included in the extracts from the accounts it was shown in the summer of 2009. Information disclosed through FOIA requests provides a wider perspective.

Concealed information: power, hierarchies and networks

The focus of Wandsworth PCT's review upon its own contract is understandable but lacks attention to important relationships. These include sub-contracting arrangements between SHL and two NHS Trusts, South West London \& St George's 
NHS Mental Health Trust (SWL\&SG), and St George's NHS Trust (SGNT), together with a GP practice. SHL's involvement with $\mathrm{DH}$ receives no mention.

During its first year of operation, SHL entered a Service Level Agreement with $\mathrm{DH}$, 'to oversee the supply and installation of digital $\mathrm{X}$-ray machines in eight prisons in England for tuberculosis (TB) screening, and for the TB Find and Treat mobile outreach project. . . The funding for these projects was unaffected by Secure Healthcare's voluntary liquidation as they went ahead before the insolvency occurred.' (Minister of State, Correspondence with MP, 10.04.12).

Information obtained through FOIA requests indicates greater complexity. Initially, DH disclosed payments it made to SHL of $£ 25,200$ in 2008, and a further $£ 195,500$ in 2009 (FOIA, DH, 22.05.13). These figures did not correspond with SHL's accounts, so a request for further information was pursued through an internal review. This resulted in disclosure of three further payments by $\mathrm{DH}$. These were of $£ 248,000$, in August 2007, of $£ 500,000$ in April 2008, and $£ 1,457,682.50$ on 4 September 2009 (FOIA, DH, 23.08.13). The final payment was made twelve days before SHL collapsed.

Payments to SHL of $£ 195,500$ in 2009 included $£ 45,500$ for staff secondments for the period from April 2009 to January 2010 (FOIA, DH, 22.05.13). DH confirmed a member of its staff was on, 'secondment out ... during the period in question to run the TB project as project manager and although he took the title Director of TB Projects he was not on the Board.' (FOIA, DH, 21.08.13). Companies House records show two companies registered on 24 October 2009, for which the former DH secondee to SHL was a director. Clarification was sought from DH seeking, who explained: 'When Secure Healthcare went into liquidation, two companies were set up to deliver the TB projects they were running.' (FOIA, DH, 21.08.13). This indicates more extensive contracting arrangements than suggested in the Minister's statement that the project, 'went ahead before the insolvency occurred.'

Wandsworth PCT's review does not consider the role of social networks that transcend organisational boundaries. These may rest upon a basis of interpersonal trust rather than contractual agreements. This is illustrated though two examples: the 
sub-contracting arrangements established with NHS organisations, and access to government funding.

Unknown to Wandsworth PCT, SHL accrued substantial debts almost from the outset. Between the commencement of the contract in July 2007 and the end of March 2008, SHL paid SWL\&SG £488,268 of $£ 879,603$ it was due. Of $£ 142,153.75$ due to SGNT, just $£ 665.00$ had been paid. The combined debts amounted to $£ 532,822.75$. (FOIA, SWL\&SG 05.04.13; FOIA, SGNT 30.04.13). A report produced by NHS London's Audit Consortium for SWL\&SG noted these debts arose despite SHL's receipt of advance payments:

'The PCT . . . often paid in advance. There was therefore no reasonable justification for delays in payment by SHL. . . Wandsworth PCT has reported that they were repeatedly asked by SHL to pay early. This provided a strong indication of cash flow difficulties at SHL, but this information was not shared with the Trust.' (FOIA, NHS London Audit Consortium via SWL\&SG, 2011: 8).

By 31 March 2009, SHL's debts to the two Trusts had risen to $£ 556,222$. When SHL collapsed six months later, SWL\&SG was owed £525,064 and SGNT owed $£ 123,501$ : a total of $£ 648,565$ (FOIA, SWL\&SG 05.04.13; FOIA, SGNT, 30.04.13).

The impact of structural secrecy is illustrated in the PCT's ignorance of SHL's debts to SWL\&SG, while the Trust was unaware of the PCT's advance payments. But other evidence suggests informal networks spanned this divide. The Chief Executive of SWL\&SG, appointed in July 2006, previously held a senior position at DH for a year, prior to which he had been a SHA Chief Executive. His appointment to SWL\&SG was overseen by the then Chief Executive of SW London SHA, and a June 2006 report to the SWL\&SG Board noted: 'The new Chief Executive will meet with the current SHA Chief Executive in her new interim role as Managing Director for South West London, within the London SHA.' (Board report to SWL\&SG, 29 June 2006). Later that year, the Managing Director for SW London was seconded to the Social Enterprise Coalition to advise on health issues (as NHS reorganisation reduced the number of SHA's), becoming Chair of SHL in 2007. Another executive director of SW London SHA became Chief Executive of Wandsworth PCT. 
Early contract negotiations included discussions between the SHL Chair and the Chief Executive of SWL\&SG to consider a reduction in payments to the Trust:

'The Trust included a $15-20 \%$ overhead in their bid price, to cover employment related overheads and any contingency. However, the Chair of SHL met the Trust's Chief Executive to request that this should be reduced to about $10 \%$. This may have involved an element of financial risk, or subsidy by the Trust.' (FOIA, NHS London Audit Consortium, 2011: $6)$.

The report notes:

'For a period of more than a year, the Trust provided services at Wandsworth Prison without having a signed sub-contractual agreement to protect its position. There were ongoing disputes with Secure Healthcare Limited, concerning the Trust's financial responsibilities and financial risk sharing. There were repeated delays in payment. However the Trust Board was not informed of these difficulties and the consequent risks for the Trust.' (FOIA, NHS London Audit Consortium, 2011: 4).

Echoing remarks in Wandsworth PCT's review, the Audit report adds: 'Documents provided to Audit show that some Trust managers informally expressed concerns about the suitability of SHL as a partner from an early stage.' (FOIA, NHS London Audit Consortium, 2010: 7). The report recommends formalised procedures for the future, with a requirement that financial risks, 'should be recognised, reported to and approved by the Board before proceeding with a tender submission.' (FOIA, NHS London Audit Consortium, 2010: 6).

A second example arises from SHL's success securing government funding. While there is no direct evidence of the role of personal and social relations, disclosed information suggests formal processes may not have been followed. On 31 July 2008 SHL secured a loan of $£ 400,000$ from the Government's Futurebuilders fund to develop capacity, 'to bid for and deliver upcoming prison healthcare contracts.' (FOIA, Cabinet Office, 19.11.12). The Cabinet Office (CO) explained: 
'As part of the standard processes in place at the time, in assessing an application for investment a risk assessment of a number of areas including both the organisation's finances and the proposal finances was undertaken. As standard this included a review of previous accounts, financial systems, and cashflow forecasts. This risk assessment was presented to the External Investment Committee and was one of the factors taken into consideration when deciding whether to make an award.' (FOIA, CO, 19.11.12).

As SHL's financial accounts were not created and approved until 5 February 2009, these could not have been available in July 2008. The Cabinet Office added:

'As part of the standard processes in place at the time, current contractors were spoken to regarding the services delivered by the applicant. At the time of assessment Secure Healthcare's main contract was with HMP Wandsworth as such the Investment officer assessing the case spoke to the Governor of Wandsworth Prison. This information was presented to the External Investment Committee and was one of the factors taken into consideration when deciding whether to make an award.' (FOIA, CO, 19.11.12).

But it was Wandsworth PCT, not HMP Wandsworth, which held the contract. When SHL collapsed in September 2009, £259,148 drawn down from this loan was written off (FOIA, CO, 19.11.12).

On 4 February 2009, the day before SHL's accounts were approved, it was awarded a second DH grant, of $£ 380,000$ to develop a 'training campus'. This was the maximum allowed under EU State Aid rules (FOIA, DH, 06.12.13). 'The Department's records show no indication that they were aware of, or had been made aware of, any significant financial risks associated with the organisation when it awarded the grant.' (National Audit Office, personal correspondence, 12.12.12). The Health Minister had previously told Parliament that Pathfinder grant decisions would involve regional assessment by SHA's against 11 criteria. These included, a clear sense of vision, purpose and innovation; robustness of governance arrangements and sufficiency of management capability; and, 'explicit commissioner support for the 
application, or a clear demonstration that the scheme will be financially viable' ( $\mathrm{HC}$ Hansard, 8 February 2007, c1207W). FOIA requests were submitted to Wandsworth PCT and NHS London seeking information about this process, producing the following responses:

'NHS Wandsworth was not asked to provide any information or advice to the Department of Health and/or NHS London on any awards made to Secure Healthcare under the Social Enterprise Pathfinder programme in 2007 or 2009. The information is therefore not held.' (FOIA, NHS SW London, 15.01.13).

'Following relevant searches, I have been informed that NHS London has not been able to locate any information relevant to your request and is therefore not in a position to disclose information to you in this instance.' (FOIA, NHS London, 13.01.13).

The NAO reported that, 'the Department $(\mathrm{DH})$ held monthly progress updates with Secure Healthcare Ltd and received written confirmation from them that the grant had been spent for the correct purposes. However, there is no evidence on file as to whether this information was verified.' (NAO, personal correspondence, 12.12.12). Writing about the training campus on 9 September 2009, in a report to the SHL Board, its chief executive acknowledged: 'We went ahead with (this) development without a tested business plan.' (FOIA, DH, SHL 2009b: 3). He describes,
'serious liquidity issues ... A number of factors have contributed to the current crisis position. It is clear we have had poor financial information to track our progress and limited cost controls ... our cost control and management data has been poor from day one... The grant and loan income injections masked the overspending.' (FOIA, DH, SHL 2009b: 3).

None of the NHS organisations seemed aware of the scale of the problem until SHL went into liquidation one week later. Apart from the two NHS Trusts, estimated £1.5 million debts included $£ 103,000$ owed to HMRC for unpaid PAYE contributions (Liquidators Report), and £150,000 due to Wandsworth PCT for services not provided (Wandsworth PCT, 2009). 
Dark secrets and clean-up work

The final section returns to my starting point, when raising questions about $\mathrm{SHL}$ as a NHS Non-Executive Director. These resulted in a review by the Appointments Commission (AC), responsible for appointing NHS Non-Executive Directors. Largely reliant upon public accounts, its report concluded:

'The award of the contract and its subsequent management and monitoring by Wandsworth PCT was distinguished by poor procedures and many failings in management. These have been attributed ... to the inexperience of the PCT's team in letting of healthcare services contracts.' (FOIA, DH, AC, 2011: 7).

'A review of the accounts of Secure Healthcare Limited for the first year of its operation show a solvent organisation with sufficient resources to meet its liabilities. . . There are weaknesses and the Secure Healthcare bid team, I conclude, let down the company ... The underlying reasons for the failure of Secure Healthcare Ltd were typical reasons for business failure and they were addressed by the management of the company as they arose without success as it turns out.' (FOIA, DH, AC, 2011: 11).

'The means by which (DH Pathfinder grant) applications were assessed and due diligence conducted from the outset ... was thorough, independent, open and externally reviewed.' (FOIA, DH, AC, 2011: 6).

Underpinning this benign assessment is an assumption that the existence of regulatory procedures and safeguards guarantees their implementation.

Commenting upon a failure of SHL to provide a copy of its business plan to Wandsworth PCT, the review concludes, 'such a plan must have existed as it would have been a pre-requisite of the $(\mathrm{DH})$ Investment Panel that one was available before consideration of a grant or loan request.' (FOIA, DH, AC, 2011: 8). The AC review excludes any consideration of possible departure from rules and normative expectations. 
A reference to the role of the liquidator also illustrates how the existence of general systems of regulation and accountability is assumed to provide safeguards. A liquidator has a duty to investigate the cause of an organisation's collapse and consider the conduct of its directors. Where there is judged to be culpability, the liquidator is required to report this to the Department of Business, Innovation and Skills (Insolvency Service). The AC review continues:

'The liquidators confirmed that they discharged their duties in both respects. Each such report is considered by the Insolvency Service to determine whether any action should be taken against any of the directors (executive or non-executive). Action would normally be taken where there was, for example, evidence of negligence, knowingly trading while insolvent, fraud etc. The reports are not made public but actions taken arising from the reports are public, especially as they generally include the striking off of the director concerned. No such action was taken.' (FOIA, DH, AC, 2011: 10).

The review's author describes this as, 'an important factor in the whole of this affair', evidently unaware of an anomaly identified in a report submitted to the Audit Committee of SWL\&SG (dated 23 February 2011). Reference to the same statement in the Liquidator's report is accompanied by this comment:

'In paragraph 4 of the report, it states that the liquidator was required to consider conduct of the company's directors and make an appropriate submission to the Department for Business, Innovation and Skill and had discharged their duties. However, on seeking further clarification on that point, (name of Liquidator) have now confirmed that there was an error in paragraph 4 and that as the company is an Industrial \& Providence (sic) Society, it is not governed by the Companies Act 1985 but the Industrial \& Providence (sic) Society Act 1965 and therefore the report normally issued to the DBIS was not required.' (FOIA, SWL\&SG, 2011: 3).

As with Wandsworth PCT's review, the sincerity of the AC report's author does not guarantee accuracy. Information required for a full analysis was not shared between NHS organisations. Of equal significance is the distinction between errors resulting 
from this 'structural secrecy' and subsequent deliberate concealment of mistakes (Vaughn, 1996: 238). On several occasions, responses to my research suggested the performance of 'clean-up work' (Vaughn, 1999), providing examples of how, 'officials develop ways both of denying the failure of the institution to perform as it should and explaining those failures which cannot be hidden' (Becker, 1967: 128).

A request to my employer for my personal data disclosed a complaint about me sent to the Vice-Chancellor of Plymouth University. The complainant alleged my concerns:

'were initially the subject of an independent review by the Appointments Committee (sic). They found no substance to MS's concerns. Indeed it was highly critical of the way he raised them. Given MS was dissatisfied with the outcome he asked the Parliamentary Ombudsman, and the Information Commissioner, to review his complaint. Again, they found no substance to MS's allegations. His complaint is now with the Department of Health. The matter has, also, been in the hands of NHS lawyers to deal with for the last two years.' (24.09.13)

On one occasion, the NHS lawyer informed me:

'You are not an investigator, regulator or statutory body and you have no standing from which to require anyone to co-operate with your lines of enquiry. None of these people are accountable to you. . . I I am in the process of drafting a Protection from Harassment letter to you regarding proceedings to seek an injunction against you.' (Personal correspondence, 23.04.13).

A FOIA disclosure request revealed the NHS lawyers were, 'paid a total of $£ 13,788.50$ for involvement with your case between 30 May 2012 and 23 August 2013.' (FOIA, DH 08.10.13). In 2015, my MP raised with the Chair of the Public Accounts Committee (PAC) contrasts between responses he received from Ministers and information disclosed through FOIA requests. The National Audit Office was asked to investigate but the PAC Chair subsequently explained that despite, 'an extensive records trawl', only limited information could be found. The NAO described the limited documentation as, 'less than satisfactory'. Records are normally destroyed after six years unless judged to be 'of value', and, 'unfortunately, some 
records of enduring value were not identified as such at the time and are no longer available.' (Correspondence from PAC Chair, 08.01.16).

A request for my personal data to the SHA with which I first raised concerns, disclosed an early internal communication describing how these should be dealt with. It ended with the words, 'Hopefully this gets put to bed today.' (02.12.11)

\section{Conclusion}

This study illustrates the contribution FOIA disclosure can make to research into contracting arrangements in the public sector. Despite limitations, disclosure of concealed data offers a valuable method for exploring hidden aspects of organisations, and researching the social organisation of 'clean-up work' that typically eludes observation. The focus upon detail in this study can now be connected with a broader issue of the social embeddedness of markets, and implications for understanding the exercise of power. Market reforms in health care rest upon neo-classical assumptions on the role of competition, which can present an, 'atomized, undersocialized conception of human action' (Granovetter, 1985: 484). Granovetter also comments on the shortcomings of approaches that acknowledge "social influences", but then, 'construe these as processes in which actors acquire customs, habits, or norms that are followed mechanically and automatically, irrespective of their bearing on rational choice.' (485). He proposes an alternative, recognising that, 'attempts at purposive action are instead embedded in concrete, ongoing systems of social relations.' (487). More specifically, he suggests, 'The embeddedness argument stresses ... the role of concrete personal relations and structures (or "networks") of such relations in generating trust and discouraging malfeasance.' (490) Arguing it is not contracts but social relations that, 'are mainly responsible for the production of trust in economic life', he notes scope for negative consequences: 'The trust engendered by personal relations presents, by its very existence, enhanced opportunity for malfeasance' (Granovetter, 1985: 491).

This approach informs three summary points on the means by which power can be exercised through concealment of 'dark secrets' using social and personal networks. These points align with three stages of the contracting process described in this 
study. Commencing with contract negotiations (and the role of interpersonal trust), these were followed by experiences of contract performance (including the emergence of the 'normalisation of deviance'), and ending with the public presentation of accounts of failure (involving concealment of dark secrets and 'cleanup work').

First, from the outset, social and personal networks existed at a senior level between SHL, the PCT, SWL\&SG NHS Trust and DH. It took two years to formalise the contract between SHL and SWL\&SG, but meanwhile informal discussions were held involving senior representatives of the two organisations that were not reported to the Trust Board. As Granovetter observes, the trust that makes discussions of this type possible can have both positive and negative consequences. Some important decisions were not formally documented, and information was not shared in recorded forms between organisations. While specific circumstances may be unique, the example highlights the wider issue of openness about performance of contractors in the NHS. Without clear and deliberate arrangements for sharing knowledge about contractors to counter the impact of structural secrecy, there is little reason to suppose something similar could not be repeated.

Examples of the 'normalisation of deviance' occurred during performance of the contract, notably in payment by the PCT for advance invoices, but also by DH in lack of rigour in grant-making processes. PCT confidence in arrangements with SHL appears to have been boosted by endorsement from those in senior positions. Not only was SHL chaired by a former SHA Chief Executive, a review of its relationship with SWL\&SG noted that a factor making involvement with SHL an attractive option for NHS organisations had been the, 'considerable enthusiasm from the Department of Health downwards, for a social enterprise model of care' (FOIA, NHS London Audit Consortium via SWL\&SG, 2010: 7). In another context, the culture of expectation such enthusiasm can generate has been described by one SHA Chief Executive, 'l've got to be able to look over my little kingdom and be able to say that the things the Government want to be happening in health care are happening on my patch. If the Prime Minister tipped up tomorrow, I could take him to a range of things to show how we are modernising the NHS.' (Storey, 2011: 636-7). This can produce a mutually reinforcing process, contributing to 'group think', and discouraging the 
raising of concerns and challenges. There were occasions when less senior staff appeared to raise questions about SHL's suitability, but these were not addressed or even clearly documented. Reflecting the 'mobilisation of bias', recurring episodes of secrecy in the NHS demonstrate the need for more effective support for those who raise concerns.

Finally, power is exercised through the selection of records to construct accounts for explaining failure, and simultaneous restriction of access to information that might allow alternative interpretations. An emphasis in official accounts upon issues of commercial expertise, attributing failure largely to technical matters, implies no wider review of policy is necessary. A more open and transparent culture could facilitate a genuine review of contracting failures in the NHS. Approaches some advocate for patient safety incidents are relevant to episodes of organisational failure. Vincent argues that an, 'incident acts as a "window" on the system', and, 'in a sense, the particular causes of the incident in question do not matter as they are now in the past. However, the weaknesses of the system revealed are still present and could lead to the next incident.' (Vincent, 2004: 242). Organisational failures may have less immediate personal impact than patient safety incidents, but nevertheless result in real costs that are paid by the public. Far greater openness is required if there is to be meaningful public accountability for arrangements established between the NHS and external health care providers.

\section{Abbreviations}

AC Appointments Commission

CO Cabinet Office

DH Department of Health

NAO National Audit Office

PCT Primary Care Trust

SGNT St George's NHS Trust

SHL Secure Healthcare Ltd 
Final author's draft of a paper published in Critical Social Policy 2017 Vol. 37 Iss. 4 pp: 520-539, (first published online in Dec. 2016). DOI: https://doi.org/10.1177/0261018316681252

SHA Strategic Health Authority

SWL\&SG South West London \& St George's NHS Trust

References

Appointments Commission (2011) Review of the Appointment of Xxxxx as Chair of xxxx Trust. Appointments Commission.

Bachrach, P. and Baratz, M.S. (1962) Two Faces of Power. The American Political Science Review. 56 (4): 947-952.

Becker, H. (1967) Whose Side Are We On? Social Problems 14/3: 234-47

British Sociological Association (2002) Statement of Ethical Practice for the British Sociological Association (March 2002). British Sociological Association

Brown K.J. (2009) Freedom of Information as a Research Tool: Realising its Potential. The Howard Journal Vol 48 No 1. February 2009 pp. 88-91

Campbell, D (2015) Far more NHS contracts going to private firms than ministers admit, figures show The Guardian, 25th April 2015

Centre for Health and the Public Interest (2015) The contracting NHS: can the NHS handle the outsourcing of clinical services? CHPI.

Department of Health (2015) Annual Report and Accounts.

Garfinkel, H. (1967/1984) Studies in Ethnomethodology. Cambridge: Polity Press

Goffman, E (1959/1990) The Presentation of Self in Everyday Life. London: Penguin.

Gould, M (2008) Healing effect The Guardian 27 February 2008

Gould, M. (2009) An ill wind blows for social enterprise The Guardian 18 November 2009

Granovetter, M. (1985) Economic Action and Social Structures: The Problem of Embededness. American Journal of Sociology. 481-510. 
Hall, P.M. (1972) A Symbolic Interactionist Analysis of Politics. In Effrat, A. (ef) Perspectives in Political Sociology. Indianapolis, New York: The Bobbs-Merrill Co.

Her Majesty's Inspector of Prisons (2004) Report on an Announced Inspection of HMP Wandsworth 17-21 May 2004 by HM Chief Inspector of Prisons. London: HMIP.

Her Majesty's Inspector of Prisons (2006) Report on a full follow-up inspection of HMP Wandsworth 10-14 July 2006 by HM Chief Inspector of Prisons. London: HMIP.

House of Commons (2010) Committee on Standards and Privileges Report Independent (2011) Singh whips up a grand expansion. Independent, 20 February 2011.

Keen, M.F. (2004) Stalking Sociologists: J Edgar Hoover's FBI Surveillance of American Sociology. New Brunswick: Transaction Publishers.

Lee, R.M (2005). The UK freedom of information act and social research International Journal of Social Research Methodology: Theory and Practice 8 (1): $1-18$

Lukes, S. (1969) Durkheim's 'Individualism and the Intellectuals' Political Studies Volume 17, Issue 1, pages 14-30, March 1969

NHS London Audit Consortium (2011) Secure Healthcare. NHS London Audit Consortium

NHS Wandsworth (2009) Prison Healthcare Services - Insolvency of Secure Healthcare Limited PCT Review. NHS Wandsworth

Royal College of Nursing (2007) Policy Briefing: Social Enterprise Update, February 2007. London: RCN.

Schnattschneider, E.E. (1960) The Semi-Sovereign People. New York: Holy, Rinehart and Winston. 
Scott, J. (1990) A Matter of Record: Documentary Sources in Social research. Cambridge: Polity Press.

Scraton, P. (2004) Speaking truth to power: experiencing critical research. In Researchers and their 'Subjects': Ethics, power, knowledge and consent. Smyth, M. \& Williamson, E. (eds.). Bristol: The Policy Press p. 177-196

Secure Health Care Ltd (2009a) Annual Return and Accounts. SHL.

Secure Healthcare (2009b) Report to SHL Board of Directors meeting, 9 September 2009. SHL

Singh, A. (2008) Where the political elite go for dinner and spicy gossip. Evening Standard. 2 December 2008.

South West London \& St George's NHS Mental Health Trust (2011) Secure Healthcare: report to Audit Committee.

Storey, J. (2011) Steering whilst rowing: governing and managing health services from the centre. Journal of Health Organization and Management. 25 (6): $625-644$

Vaughn, D. (1996) The Challenger Launch Decision. Chicago: University of Chicago Press.

Vaughn, D (1999) The Dark Side of Organizations: Mistake, Misconduct and Disaster. Annual Review of Sociology. 25: 271-305.

Vincent, C.A. (2004) Analysis of clinical incidents: a window on the system not a search for root causes Quality and Safety in Health Care 2004;13: 242-243

Wilks-Heeg, S (2015) Revolving-Door Politics and Corruption. In Whyte (2015).

Report of Wandsworth Borough Council Overview and Scrutiny Committee, 28.10.09

Whyte, D. (ed) (2015) Introduction: A Very British Corruption in How Corrupt is Britain? London: Pluto Press. 